\title{
Proto-oncogenes in a eukaryotic unicellular organism play essential roles in plasmodial growth in host cells
}

\author{
Kai $\mathrm{Bi}^{1,2}$, Tao Chen ${ }^{2}$, Zhangchao $\mathrm{He}^{1,2}$, Zhixiao Gao ${ }^{1,2}$, Ying Zhao ${ }^{1,2}$, Yanping $\mathrm{Fu}^{2}$, Jiasen Cheng ${ }^{1,2}$, Jiatao Xie ${ }^{1,2}$ and \\ Daohong Jiang ${ }^{1,2^{*}}$ (D)
}

\begin{abstract}
Background: The eukaryotic unicellular protist Plasmodiophora brassicae is an endocellular parasite of cruciferous plants. In host cortical cells, this protist develops a unicellular structure that is termed the plasmodium. The plasmodium is actually a multinucleated cell, which subsequently splits and forms resting spores. The mechanism for the growth of this endocellular parasite in host cell is unclear.

Results: Here, combining de novo genome sequence and transcriptome analysis of strain ZJ-1, we identified top five significant enriched KEGG pathways of differentially expressed genes (DEGs), namely translation, cell growth and death, cell communication, cell motility and cancers. We detected 171 proto-oncogenes from the genome of $P$. brassicae that were implicated in cancer-related pathways, of which 46 were differential expression genes. Three predicted proto-oncogenes (Pb-Raf1, Pb-Raf2, and Pb-MYB), which showed homology to the human protooncogenes Raf and MYB, were specifically activated during the plasmodial growth in host cortical cells, demonstrating their involvement in the multinucleate development stage of the unicellular protist organism. Gene networks involved in the tumorigenic-related signaling transduction pathways and the activation of 12 core genes were identified. Inhibition of phosphoinositol-3-kinase relieved the clubroot symptom and significantly suppressed the development process of plasmodia.
\end{abstract}

Conclusions: Proto-oncogene-related regulatory mechanisms play an important role in the plasmodial growth of $P$. brassicae.

Keywords: Plasmodiophora brassicae, Proto-oncogenes, Clubroot, Cancer, Tumor, Brassica napus

\section{Background}

Plasmodiophora brassicae Woron. is an obligate intracellular plant parasite in the protist subgroup Rhizaria [1]. It is one of the most economically important pathogens of cruciferous plants [2]. P. brassicae induces galls on the infected roots of cruciferous plants, such as oilseed rape and cabbage [3]. It severely disrupts the host root functions by inducing the formation of deformed galls, which reduce the uptake of water and nutrients from the soil and the growth of the roots [4]. Clubroot causes

\footnotetext{
* Correspondence: daohongjiang@mail.hzau.edu.cn

${ }^{1}$ State Key Laboratory of Agriculture Microbiology, Huazhong Agricultural University, Wuhan 430070, Hubei Province, People's Republic of China ${ }^{2}$ Provincial Key Laboratory of Plant Pathology of Hubei Province, College of Plant Science and Technology, Huazhong Agricultural University, Wuhan 430070, Hubei Province, People's Republic of China
}

huge economic losses to oilseed rape and cruciferous vegetable crops, accounting for up to $10-15 \%$ loss of cruciferous crops production globally $[5,6]$.

When host signals (root exudates) are sensed, the resting spores of $P$. brassicae germinate and release primary zoospores. The zoospores attach to and invade the root hairs. $P$. brassicae forms primary plasmodia and primary zoosporangia in root hairs. This process is termed the asymptomatic root hair infection stage $[2,7]$. The secondary zoospores are released from the broken root hairs and directly invade host cortical cells. P. brassicae forms galls on host roots or rootlets by the modification of hormone levels [8-11]. In the cortical cells, $P$. brassicae form the secondary plasmodia [12]. In each plasmodium, the nuclei continuously divide, but the plasmodium does not split. Thus, a plasmodium is a single

(c) The Author(s). 2018 Open Access This article is distributed under the terms of the Creative Commons Attribution 4.0 International License (http://creativecommons.org/licenses/by/4.0/), which permits unrestricted use, distribution, and reproduction in any medium, provided you give appropriate credit to the original author(s) and the source, provide a link to the Creative Commons license, and indicate if changes were made. The Creative Commons Public Domain Dedication waiver (http://creativecommons.org/publicdomain/zero/1.0/) applies to the data made available in this article, unless otherwise stated. 
cell with multiple nuclei. After meiotic cleavage, the multinuclear plasmodium returns to the haploid state [13]. Finally, the internal space of plant cells become filled with the mature resting spores [12].

The genome sequences of the single spore isolate Pbe3, $\mathrm{Pb} 3$, and $\mathrm{Pb} 6$ of $P$. brassicae have been determined. In addition, studies have shown that the significant reduction in intergenic space and low repeat content contribute to the compact genome of $P$. brassicae, and some genes involved in the regulation of the plant growth hormones (cytokinin and auxin) and ancestry of chitin synthases have been identified [3, 14]. These genome data have helped clarify the biological properties of $P$. brassicae. However, the mechanisms involved in special developmental stages of $P$. brassicae, especially the cell division events of multinucleate secondary plasmodia during cortical infection, remain unclear. This prompted us to investigate the molecular regulation mechanisms of the pathogen in response to growth and development characteristics by the combined de novo genome sequencing and transcriptome analysis of cell type-specific stages.

Multicellular organisms have evolved more sophisticated, higher-level functional capability by a division of labor among component cells with complementary behaviors [15]. However, dissolution and death of multicellular individuals due to conditions like cancer occur when the cooperation of component cells in multicellular species breaks down $[16,17]$. When cells of multicellular organism fail to regulate their growth within the normal program of development, they face the challenge of cancer, which has often been described as a loss of multicellularity.

Unlike the closely regulated and controlled growth of normal cells, most malignant cells have some common features, including a strong proliferative activity, self-sufficiency in growth signals, limitless regulation of replicative potential (in which antigrowth signals are ignored and replication continues in the presence of a growth signal), and evasion of cell death by a variety of pathways [18]. Cancer occurs in almost all metazoans in which adult cells proliferate, which suggests that the regulatory mechanism of tumorigenic cells is deep-rooted in the evolutionary history of metazoans [19]. The $c-m y c$ proto-oncogene encodes a transcription factor (Myc) with oncogenic potential. Genetic studies of an ancestral myc proto-oncogene from Hydra have dated the human oncogene $m y c$ back at least 600 million years $[20,21]$. It has been argued that oncogenes are ancient and highly conserved, and that cancer cells are not newly evolved types of cell, but rather are heirs to a basic mode of survival that is deeply embedded in multicellular life. In this scenario, cancer is an atavistic state of multicellular life [19].

The possibility of the existence of cancer in other multicellular organisms or even in unicellular protozoa is contentious [22-24]. Despite the demonstration that differentiated plant cells have the unique potential of reverting to a pluripotent state, proliferating, and transdifferentiating, the current knowledge suggests that plant cells are highly resistant to oncogenic transformation and strikingly tolerant to altered levels of cell-cycle regulators and to hyperplasia [25]. So far, it is still unclear whether the regulatory mechanism of tumorigenic cells is involved in the growth and development of unicellular protozoa.

The current study is an initial multi-omics analysis aimed at providing novel insights into the regulatory pattern of the critical multinucleate cell division lifestyle of $P$. brassicae. The data suggest that mechanisms of the proto-oncogenes are highly conserved and deep-rooted in evolutionary history, and play important roles in the specific developmental stage of the examined eukaryotic unicellular organism.

\section{Results}

\section{Cell type-specific transcriptome analysis of $P$. brassicae}

Adopting a whole-genome shotgun sequencing strategy, a combined de novo genome sequence data and cell typespecific transcriptome analysis of $P$. brassicae, including multinucleate secondary plasmodia stage, we constructed the final $24.1 \mathrm{Mb}$ genome assembly with high-quality clean reads.

During the cortical stage of its life cycle, $P$. brassicae can be multinucleate in a cell termed the plasmodium (Fig. 1a). The transition from the unicellular state to the multinucleate secondary plasmodium with a rapidly proliferating cell type is an important course of cell developmental. It leads to the formation of galls containing mononucleate resting spores that occupy most of the cell [12, 26] (Fig. 1b, c). To investigate the transition from unicellular cells to multinucleate secondary plasmodia, we conducted transcriptome analysis of $P$. brassicae at three time points-the unicellular resting spore (RS) stage, unicellular germinating resting spore (GS) stage (Fig. 1d), and multinucleate early cortical infection (IN) stage. Compared to the RS stage, in the IN stage 508 genes were up-regulated and 89 genes were down-regulated.

Furthermore, compared with the GS stage, the germination of the resting spores and release of primary zoospores in the IN stage were associated with the up-regulation of 594 genes and the down-regulation of 86 genes (Fig. 2a). The majority of the differentially expressed genes (DEGs) were up-regulated during the IN stage with multinucleate secondary plasmodia (Fig. 2a and Additional file 1: Figure S1), suggesting that the transition from unicellular to the multinucleate state is critical for the whole cell developmental biology of $P$. brassicae.

To confirm the RNA-Seq profiles, qRT-PCR was conducted on 12 randomly selected DEGs. The data between RNA-Seq and qRT-PCR of the genes displayed a high correlation, indicating the basic consistency between the two approaches (Additional file 2: Figure S2 and and Additional file 3: Table S1). To further understand the function of these 


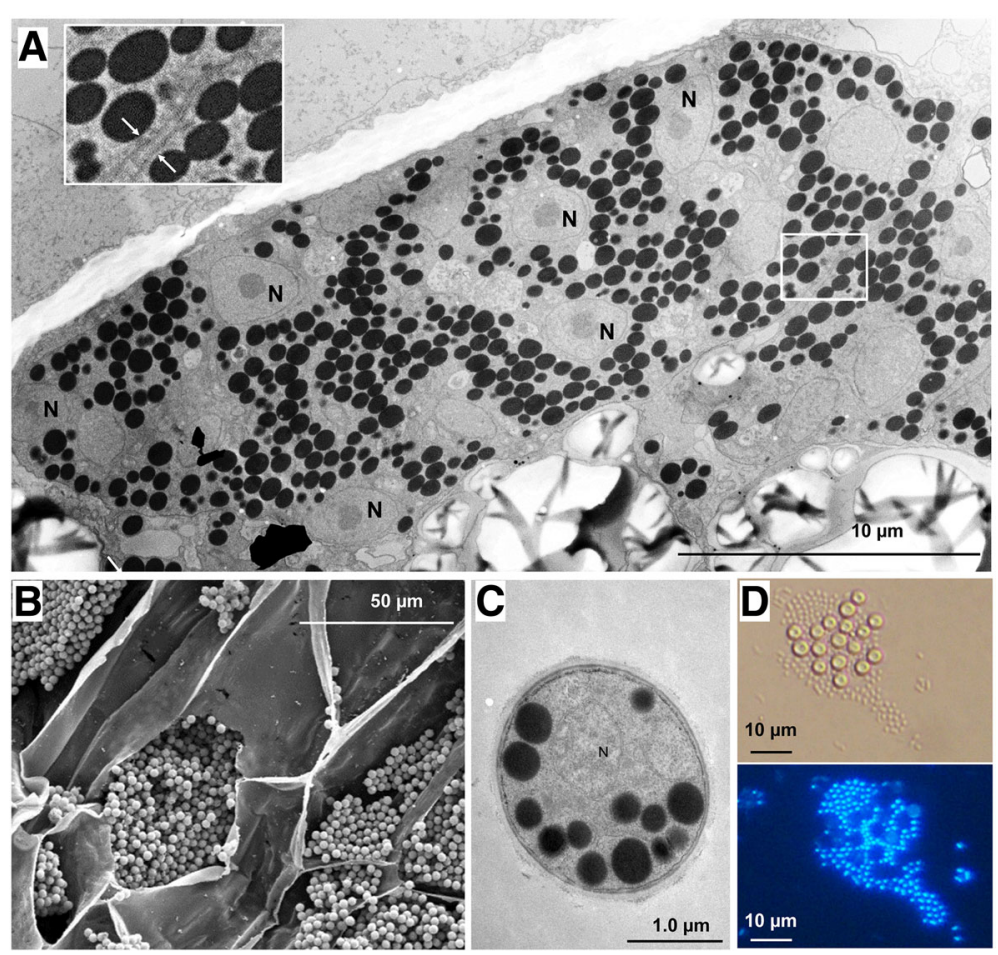

Fig. 1 Plasmodia, resting spores, and germination of resting spores (zoospores) of $P$. brassicae. a Multinucleate plasmodia in a root cortical cell of B. napus; the left upper corner shows an enlarged portion from the white square frame showed membranes of two plasmodia (white arrows); $\mathrm{N}$, nucleus. b Mature resting spores in cortical cells of roots of B. napus. c Resting spores observed by transmission electron microscopy. $\mathbf{d}$ Germinated resting spores (large) and zoospores (small) stained with 4',6-diamidino-2-phenylindole. The resting spores are empty, with no nuclei present

DEGs, gene ontology (GO) term enrichment analysis was performed. The GO categories were ranked based on $P$-values. The significantly enriched classes $(P \leq 0.05)$ are presented. For these DEGs during multinucleate secondary plasmodia stage, the most significantly enriched GO terms were GO: 0030154 cell differentiation, GO: 0040007 growth, GO: 0000003 reproduction, GO: 0006412 translation in biological processes level, GO: 0005623 cell, GO: 0030312 external encapsulating structure, GO: 0005622 intracellular, GO: 0043226 organelle, and GO: 0005198 structural molecule activity in molecular functions level (Fig. 2B). Furthermore, qRT-PCR verified that 15 randomly selected genes from the significant GO Classification Enrichment were dramatically activated during the multinucleate secondary plasmodia stage (Fig. 2c and Additional file 3: Table S1). Cell type-specific transcriptome analysis revealed the conversion from unicellular to multinucleate status during $P$. brassicae cell developmental.

\section{Proto-oncogene mechanism involved in the specific developmental stage of multinucleate plasmodium}

Infected plant roots transform into galls, with multinucleate secondary plasmodia cell division taking place rapidly. In the process, the secondary zoospores first become myxamoebae and then invade internal root tissues, where they become multinucleate secondary plasmodia [26]. The spherical or subspherical young plasmodia divide into several small plasmodia and the small multinucleate plasmodia form a cluster by repeated cell division. The plasmodia fuse with each other, which is followed by the development of vegetative plasmodia. At the end of cortical infection stage, the mature resting spores form [27] (Fig. 1b).

Based on Kyoto Encyclopedia of Genes and Genomes (KEGG) pathway analysis, we identified 171 proto-oncogenes that were implicated in the "Cancers" (Human Diseases) related pathways from the $P$. brassicae ZJ-1 genome, of which 46 genes were DEGs (Additional file 4: Table S2). Of these 171 proto-oncogenes, three predicted proto-oncogene proteins from $P$. brassicae-PbRaf-1 (PlasB_06593), PbRaf-2 (PlasB_09434) and Pbmyb (PlasB_01331)-were found to contain conserved functional domains (S_TKc and myb) homologous with Raf and myb proto-oncogenes proteins from Homo sapiens, respectively (Fig. 3a, b). Raf and myb proto-oncogenes proteins regulate fundamental cellular processes such as growth, proliferation, differentiation, metabolism, and apoptosis, and the deregulation of Raf and $m y b$ proto-oncogenes is frequently observed in tumorigenesis [28-30]. Presently, these three predicted protooncogenes from $P$. brassicae were specifically activated with the rapidly proliferating multinucleate plasmodium cell type 

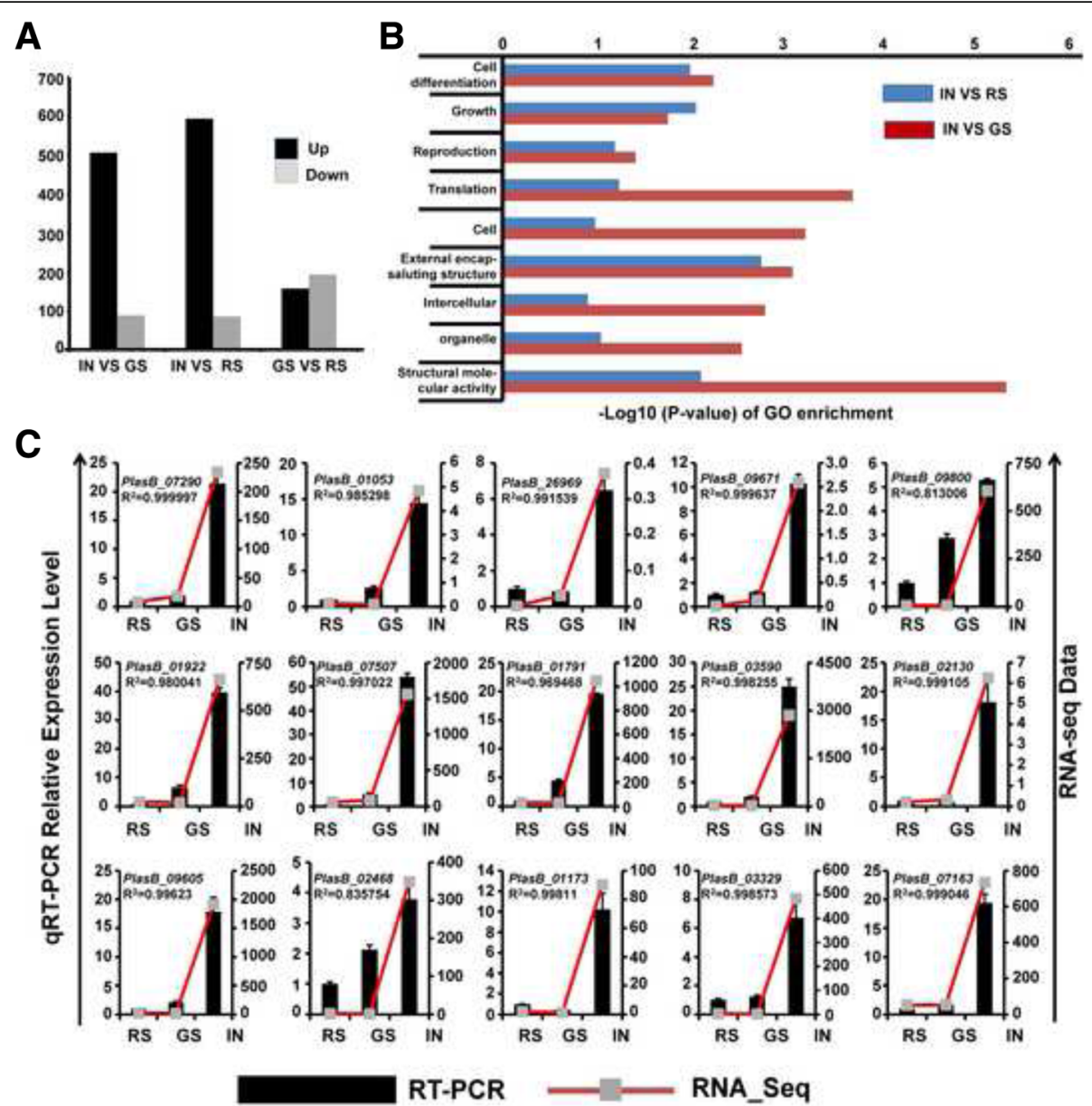

Fig. 2 Transcriptome analysis of the entire infection process of $P$. brassicae. a DEGs during the infection stages. The early cortical infection stage (IN) was compared with the RS (resting spores) stage and GS (germinating resting spores) stage. b Significantly enriched Gene Ontology (GO) terms $(P<0.05)$ of DEGs from the comparison of IN-VS-RS and IN-VS-GS. GO terms belong to biological processes (GOBP), cellular components (GOCC), and molecular functions (GOMF) were shown, respectively. GO terms were sorted based on P-values. c Validation of $G O$ enrichment of DEGs by qRT-PCR. Fifteen DEGs from significant GO Classification Enrichment were chosen randomly for qRT-PCR validation. The relative expression level of each gene was expressed as the fold-change between three different samples (RS, GS, IN) in the RNA-Seq data (red line chart) and qRT-PCR data (black histogram). Data from qRT-PCR represent the means and standard deviations (three replications). The actin gene was used as an internal control to normalize the expression data. Pearson's correlation coefficient ( $R$ value) was used to measure the consistency of the RNA-seq data and qRT-PCR. DEGs from Biological Process: PlasB_07290, PlasB_01053, PlasB_26969, PlasB_09671; DEGs from Cellular Component: PlasB_02130, PlasB_09605, PlasB_02486, PlasB_01173, PlasB_03329, PlasB_07163; DEGs from Molecular Function: PlasB_09800, PlasB_01922, PlasB_07507, PlasB_01791, PlasB_03590. See Additional file 4: Table S2 for putative functions of these genes. See Additional file 5: Table S3 for genes information

(Fig. 3c). This indicated that the proto-oncogene-related cancer cell development pathway may be highly conserved and deeply embedded in multicellular life and in unicellular protists.

We conducted KEGG pathway classification enrichment analysis on significantly enriched DEGs $(P \leq 0.05)$. During the IN stage, the top five significantly enriched DEGs identified in the KEGG pathway classifications were "Translation" (Genetic information processing), "Cell growth and death", "Cell communication", "Cell motility" (Cellular Processes), and "Cancers" (Human Diseases). However, the tendency of this significant enrichment of pathways was no longer evident at the GS stage (Fig. 4a). Furthermore, qRT-PCR analysis verified 18 randomly chosen genes from those significantly enriched in the KEGG pathway. "Translation" and "DNA replication" (Genetic information processing), "Cell growth and death", "Cell communication", "Cell motility" (Cellular processes), and "Cancer" (Human diseases) were dramatically activated during the multinucleate plasmodium developmental stage (Fig. 4b and Additional file 3: Table S1). Our results suggest that the "Translation" and "DNA replication", "Cell growth and death", "Cell communication", "Cell motility" and "Cancer" 


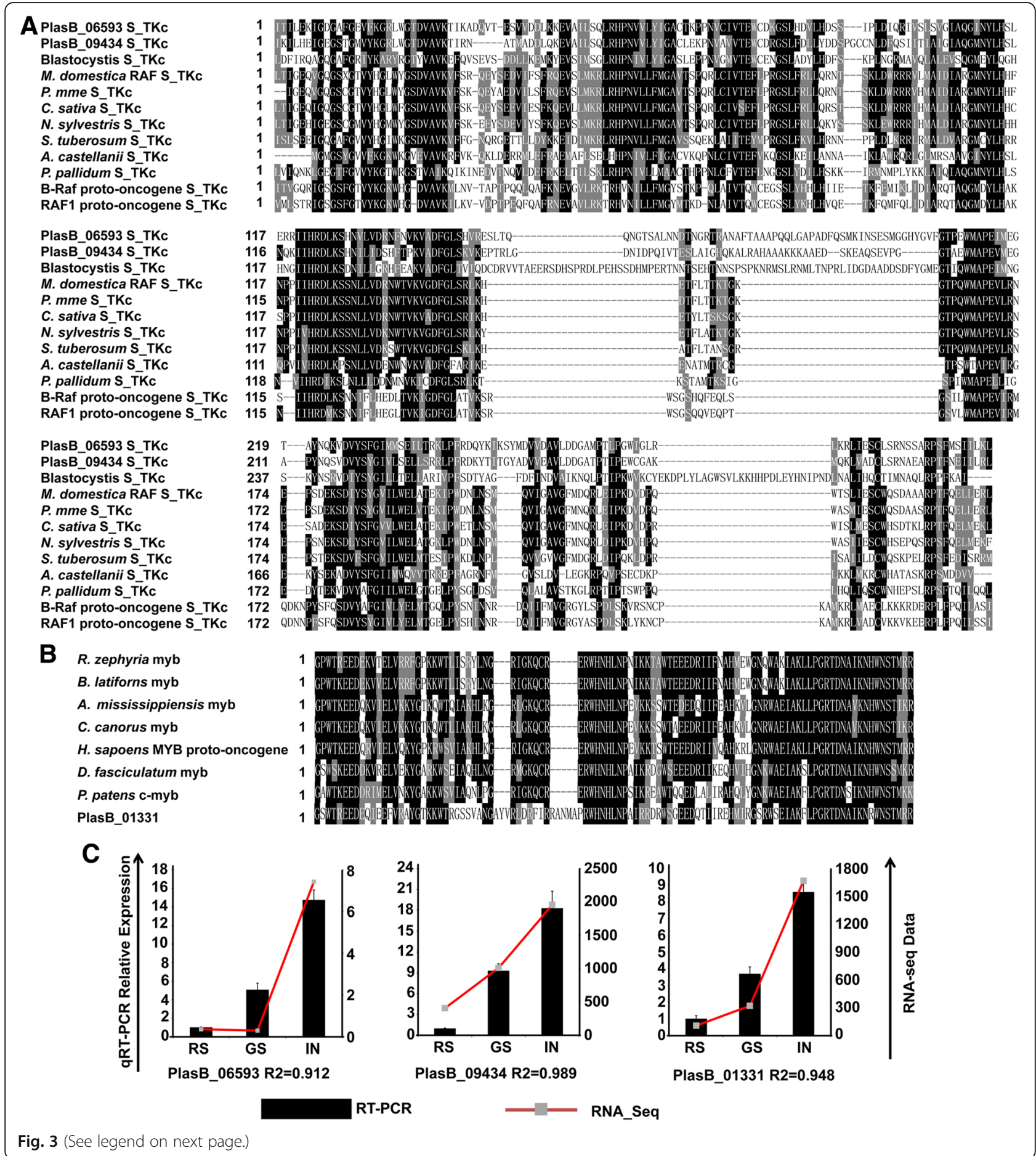




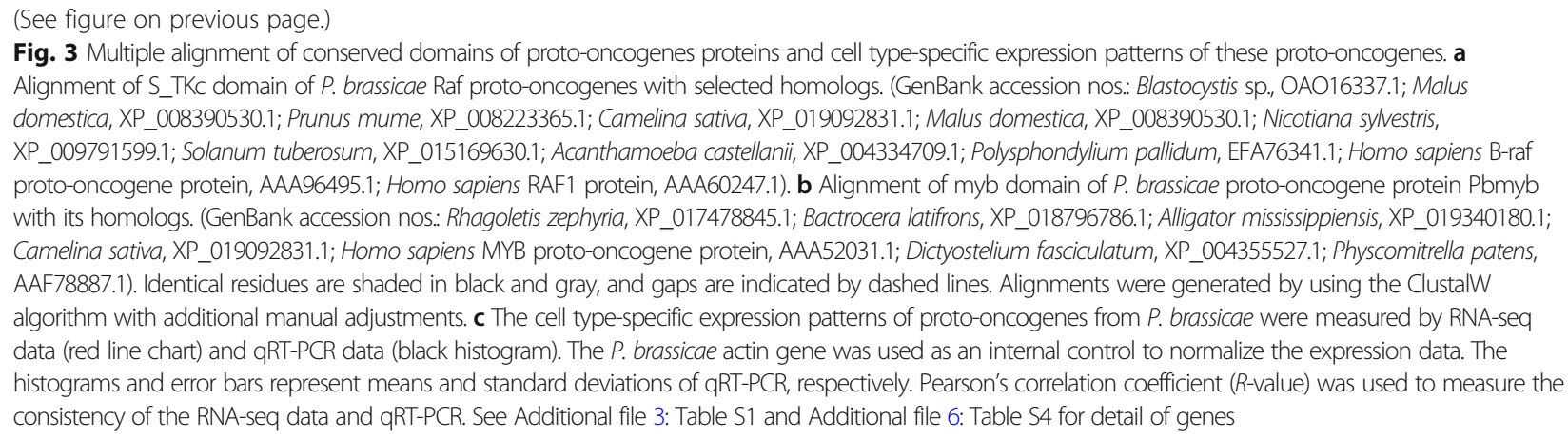

KEGG pathways are distinctively activated and are important in the transition from the unicellular to multinucleate plasmodium states with the rapidly proliferating cell type during cortical infection. The findings reveal the sophisticated mechanism of the proto-oncogene-related pathways by which the pathogen can switch from the normal unicellular state to the continuously dividing tumorigenic state.

\section{Phosphoinositol-3-kinase (PI3K) inhibitor treatment relieves the severity of clubroot symptom}

Extensive research over the past decade has revealed the critical role for the signaling transduction pathways in the regulation of the dynamic process of tumorigenesis. The dysregulation of these pathways, for example the Ras/PI3K-Akt and mammalian target of rapamycin (mTOR) signaling pathways, lead to massive overgrowth of tissue [31-33]. The present organization analysis identified 17 gene-encoded proteins containing conserved domains, which were predicted to be involved in cancer-related signaling pathways in the genome of $P$. brassicae (Fig. 5a, Additional file 5: Table S3, and Additional file 6: Table S4). qRT-PCR confirmed the expression pattern of the selected core components of the Ras/ PI3K-Akt and mTOR signaling pathways during the developmental stage of the multinucleate plasmodium. The findings indicate the specific activation of the Ras/ PI3K-Akt and mTOR signaling pathways during the cortical infection. Compared with other developmental stages, the core genes involved in the Ras/PI3K-Akt signaling pathway (Regulation of actin cytoskeleton), Ras/MAPK signaling pathway (Cell proliferation), PI3K-Akt signaling pathway (Survival signal, Growth and proliferation, Cell cycle progression, Cell survival, Protein synthesis), and mTOR signaling pathway (Translation, Cell growth) were significantly activated in the rapidly proliferating cell stage (Fig. $5 \mathrm{~b}$ and Additional file 3: Table S1). The transcriptome analysis of $P$. brassicae genes and gene networks involved in tumorigenicrelated signaling transduction pathways documented the activation of the core components of the Ras/PI3K-Akt and mTOR signaling pathways, providing insights into the mechanisms by which the parasite can change the normal growth and development into a tumorigenic life-style.

Due to the feature of obligate biotrophy, there is still no successful and stable genetic transformation system for $P$. brassicae. Thus, we conducted inhibitor treatment experiments to explore the requirement of tumorigenesis-related signaling transduction pathways during the tumorigenic proliferating process of the multinucleate plasmodium stage. GDC-0032 is a potent, next-generation $\beta$ isoform-sparing PI3K inhibitor targeting $\mathrm{PI} 3 \mathrm{~K} \alpha / \delta / \gamma$ [34, 35]. GDC-0032 treatment affects the normal growth and root formation and plant development of oilseed rape plants (Brassica napus). The expression of Cyclin (XM_013809141.1) from B. napus between the mock-treated and GDC-0032-treated groups did not differ significantly (Additional file 7: Figure S3 a, b). Host plants were inoculated with GDC-0032-pretreated resting spores and then grown in nutrient solution that contained the inhibitor. GDC-0032 had no effect on the germination rate of the resting spores or the root hair infection rate of $P$. brassicae (Additional file 7: Figure S3 c, d). Clubroot symptom was then quantified at 21 and 28 days post-infection (dpi). Clubroot symptom was less frequent in the inhibitor-treated plants with a lower Disease Index (DI) than the mock-treated group (Fig. 6a, b). qPCR was used to evaluate the relative accumulated amount of pathogen in the root tissues of host plants. P. brassicae was 37 -fold more prevalent in the infected roots of mock-treated group than the inhibitor-treated group (Fig. 6c). Furthermore, the expression levels of the components from PI3K-related signaling transduction pathways were significantly reduced in the inhibitor-treated group (Fig. 6d). These results indicated that GDC-0032 treatment could relieve clubroot symptom of infected roots by inhibiting the core components of PI3K signaling transduction.

\section{Discussion}

\section{Conversion from unicellular to multinucleate state is the key stage of $P$. brassicae cell development}

The conversion from the unicellular state to multinucleate secondary plasmodium is critical in P. brassicae cell developmental biology, as the cell division of secondary plasmodia 

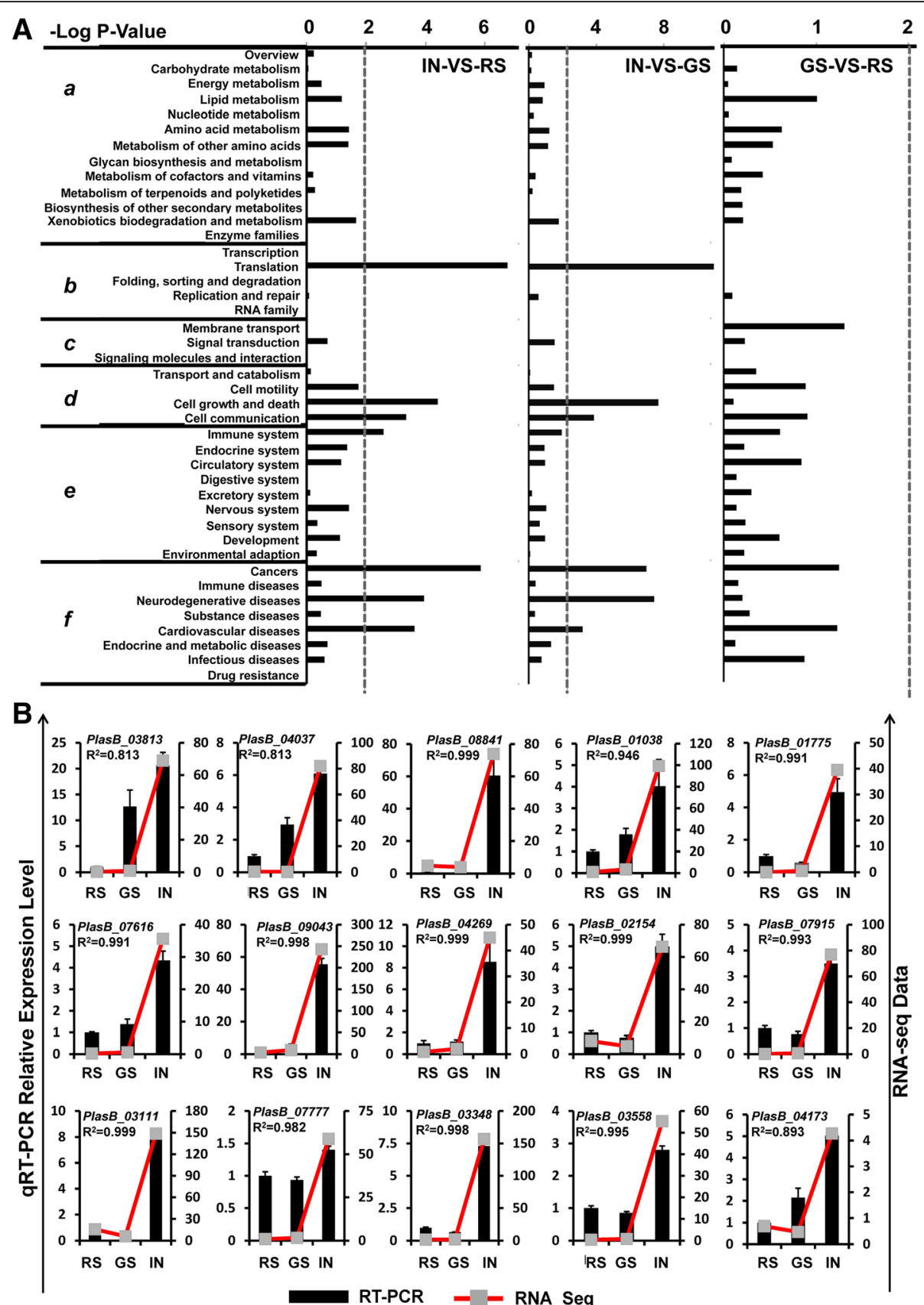

Fig. 4 KEGG pathway classification enrichment of DGEs of $P$. brassicae in three developmental stages. a Enriched pathways. X-axis, the significance (-Log P-value) of KEGG Pathway Enrichment was calculated by the method of hypergeometric distribution; Y-axis, the category of KEGG Pathway (a, Metabolism; b, Genetic Information Processing; c, Environmental Information Processing; d, Cellular Processes; e, Organismal Systems; $f$, Human Diseases). Vertical dotted lines: $P=0.01$. b Eighteen DEGs from significant KEGG Pathway Classification Enrichment were randomly selected for qRT-PCR validation. The relative expression level of each gene was expressed as the fold change between three different samples (RS, GS, IN) in the RNA-Seq data (red line chart) and qRT-PCR data (black histogram). The P. brassicae actin gene was used as an internal control to normalize the expression. Data from qRT-PCR represent the means and standard deviations. Pearson's correlation coefficient ( $R$-value) was used to measure the consistency of the RNA-seq data and qRT-PCR. Up, middle and down panes, DEGs from Translation and DNA replication KEGG Pathway, Cell growth and death KEGG Pathway and Cancers KEGG Pathway, respectively. See Additional file 4: Table S2 for the information of the putative genes 


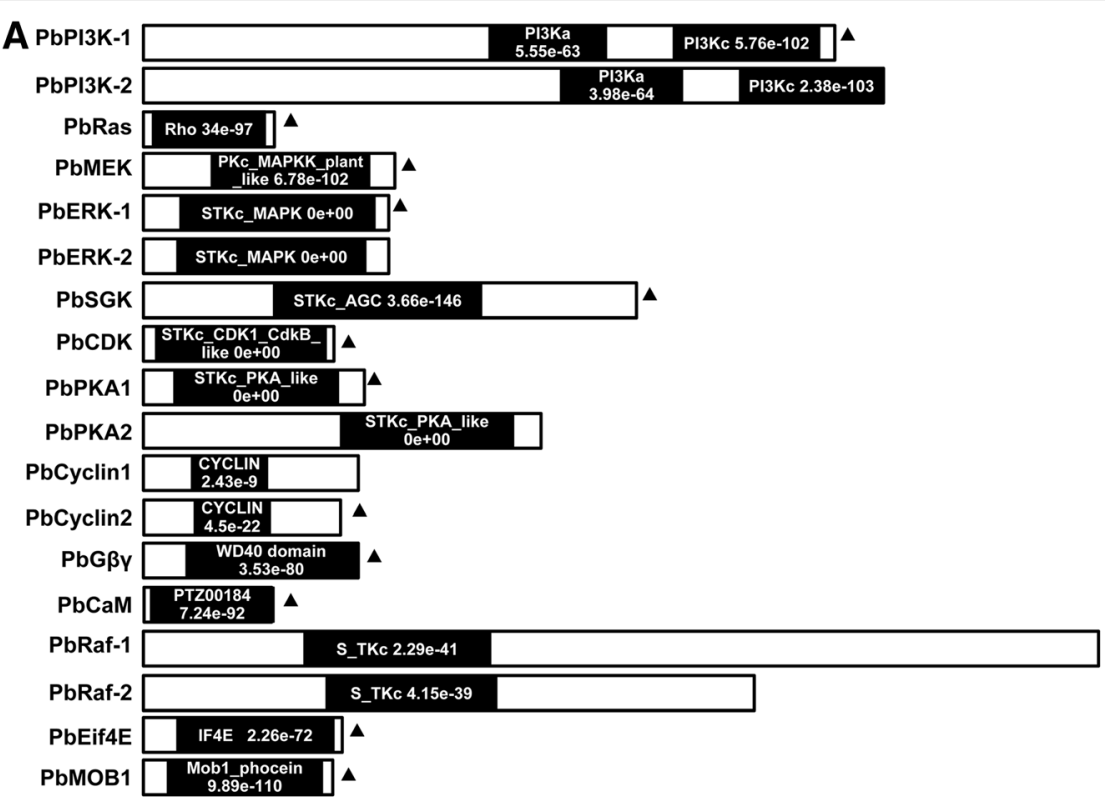

B

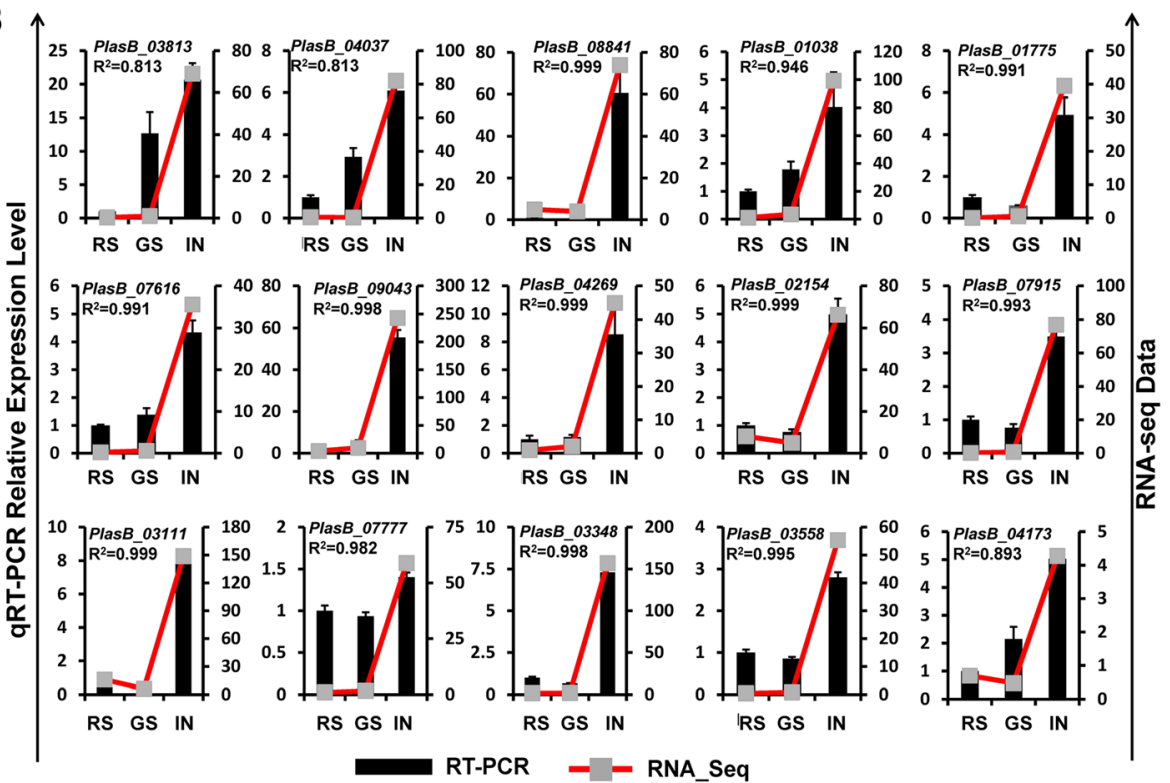

Fig. 5 Proteins involved in cancer-related signaling pathways in P. brassicae and qRT-PCR validation of the expression pattern. a Schematic diagram of proteins encoded by genes of cancer-related signaling pathways in $P$. brassicae. The black frames represented conserved domains in the genes encoded proteins. The information of conserved domain, e-value, and length was obtained from NCBI database. $\mathbf{b}$ Twelve core genes of cancer-related signaling pathways (marked with black solid triangle in (a) were chosen for qRT-PCR validation. Expression levels of these 12 genes from the three different samples (RS, GS and IN) were measured by RNA-seq data (Red line chart) and qRT-PCR data (black histogram). The actin gene of $P$. brassicae was used as an internal control to normalize the expression level. Data from qRT-PCR represent the means and standard deviations (three replications). $R$-value of Pearson's correlation coefficient was used to measure the consistency of the RNA-seq data and qRT-PCR. See Additional file 3: Table S1 and Additional file 4: Table S2 for genes information

provokes the rapidly cleavage into resting spores, which enable survival during harsh environmental conditions and the initial infection source of the next cycle [12]. The rapidly proliferating cell types of multinucleate plasmodia are part of this conversion. The formation of secondary plasmodia is accompanied by hypertrophy and hyperplasia of the infected host cells, leading to the development of galls that obstruct nutrient and water transport, with resting spores released back into the soil when the galls decompose [14]. Although the transition from the unicellular to the multinucleate state has been the focus of $P$. brassicae infection biology research for a long time [12, 26], there is still a poor understanding of this phase change, in particular, the details of the transcriptional regulatory network of multinucleate 


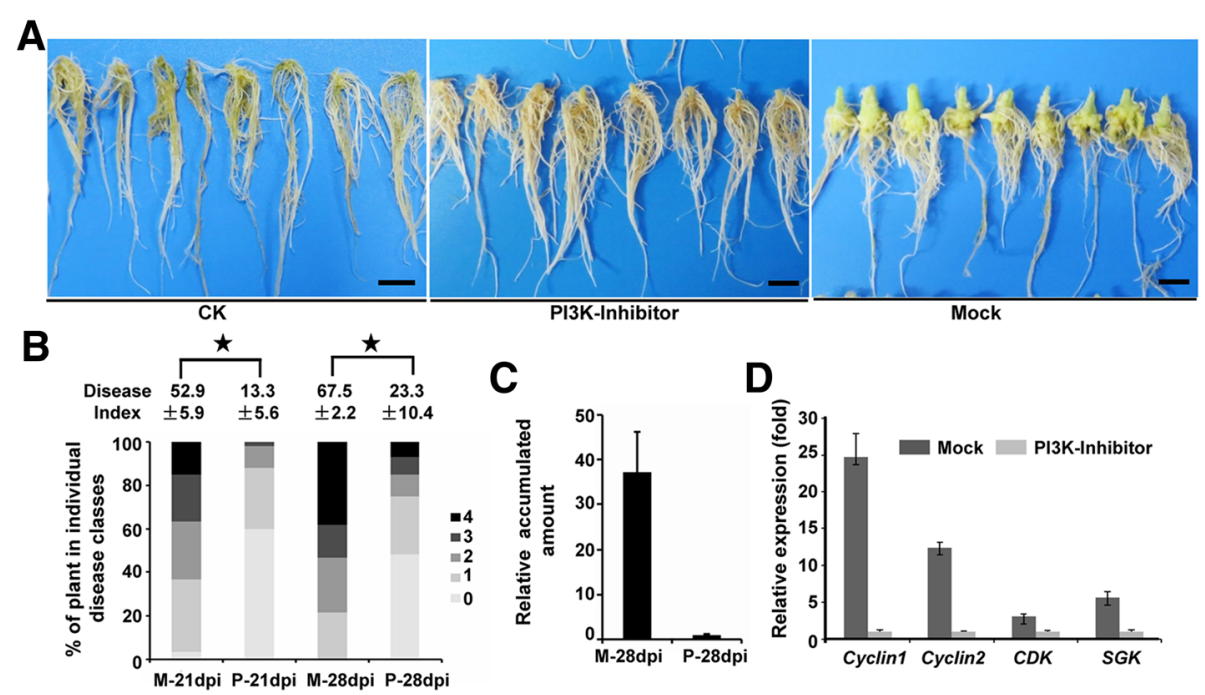

Fig. 6 Effect of PI3K inhibitor treatment on the clubroot symptom of B. napus. a PI3K-treated and P. brassicae-inoculated plants showed less symptom and rich rootlets; non-inoculated plants are shown as control (CK), and plants inoculated P. brassicae showed heavy symptoms (mock). Photographs were taken at 28 dpi. Bar denotes $1 \mathrm{~cm}$. b Clubroot symptoms of infected roots from three biological replicates were evaluated using the percentage of plants in individual disease classes and disease index (DI) at $21 \mathrm{dpi}$ and $28 \mathrm{dpi}$. Asterisks indicate statistically significant differences at the level of $P=0.05$. M: Mock-treated P: PI3K inhibitor-treated. c At 28 dpi, the infected roots of mock-treated plants and inhibitor-treated plants were harvested. The relative accumulated amount of pathogen DNA was quantified by qPCR. The actin gene of $B$. napus was set as the control to normalize the accumulation amount of the pathogen. M, mock treated; P, PI3K inhibitor-treated. $\mathbf{d}$ The expression levels of genes from PI3K-related pathways between mock-treated and inhibitor-treated groups. The $P$. brassicae actin gene was used as an internal control to normalize the expression level. The expression level of inhibitor-treated groups was set as 1.0. Data represent the means and standard deviations

secondary plasmodium. Understanding the mechanisms involved in cell division of multinucleate secondary plasmodia could help reveal the universal regulation pattern of cell division and development of multinucleate cells in this type of protist.

Presently, GO enrichment analysis of cell type-specific transcriptome suggested that the activation of cell differentiation, growth, reproduction, and translation related biological processes are required in multinucleate cell division. Based on the functional study of the significantly enriched KEGG pathways, we speculate that many pathways, including "Cancer" (Human Diseases) maybe vital for the conversion from a normal unicellular state to the rapidly proliferating multinucleate cell state.

\section{Proto-oncogenes of $P$. brassicae are specifically activated during the multinucleate cell division stage}

The 171 proto-oncogenes implicated in the "Cancer" (Human Disease) pathway were mined from the genome of strain ZJ-1 by in silico analysis. Proto-oncogenes may be ancient and highly conserved [36]. Such conservation indicates that proto-oncogenes are normal cellular genes homologous to oncogenes, but they have served vital and indispensable functions in normal cellular and organismic physiology, and that their role in carcinogenesis represents only an unusual and aberrant diversion from their usual functions $[19,36]$. For example, the deregulation of the $c-m y c$ proto-oncogene leads to tumorigenesis and is a hallmark of approximately
$30 \%$ of all human cancers $[37,38]$. The ancestral forms of $m y c$ and $\max$ genes have been identified and extensively characterized in the early diploblastic cnidarians, Hydra magnipapillata [20]. The myc gene was observed to be specifically activated in all rapidly proliferating cells, such as the interstitial stem cell system and gland cells. However, the expression of $m y c$ is not detectable in terminally differentiated nerve cells, nematocytes, or epithelial cells. The results reveal that the stem cell-specific activation of the ancestral myc protooncogene is indispensable for the regenerative ability of the early metazoan Hydra, which confirms that the principal functions of the Myc master regulator arose very early in metazoan evolutionary history [20].

The present findings corroborate the requirement of 171 proto-oncogenes in the multinucleate cell division stage to regulate proliferation and self-renewal and to perturb or inhibit terminal differentiation, as has been proposed in metazoans. For the S_TKc and myb conserved functional domains, three predicted proto-oncogenes proteins from $P$. brassicae displayed homology with Raf and myb from $\mathrm{H}$. sapiens, respectively. These proto-oncogenes were specifically activated during the cell type-specific multinucleate cell division course of $P$. brassicae. Considering the indispensable role of proto-oncogenes from the protist subgroup Rhizaria in cell developmental biology, similar to the rapid cell proliferation of multinucleate plasmodia, we suggest that the proto-oncogenes are a group of genes that have been strongly functionally conserved in metazoans and protists. 
PI3K-related signaling transduction pathways have key roles during multinucleate cell division stage

PI3K-Akt signaling, including downstream signaling pathways, such as the mitogen-activated protein kinase kinase (MEK), extracellular signal-regulated kinase (ERK), mitogenactivated protein kinase (MAPK) pathways and the mTOR pathways, are activated by many types of cellular stimuli or toxic insults. This activation regulates the fundamental cellular functions of transcription, translation, proliferation, growth, and survival $[32,39]$. The development and progression of cancer are the result of a disturbance in the balance between cell proliferation and apoptosis [40]. PI3K-Akt signaling is associated with cell proliferation and apoptosis. Notably, many studies have demonstrated that the constitutive activation of the PI3K-Akt pathway is frequently associated with human cancers [32, 41, 42]. These findings indicate that the PI3K-Akt pathway plays a pivotal role in tumor progression. Genes associated with tumorigenicrelated signaling transduction pathways were identified from $P$. brassicae. Our transcriptome analysis also revealed the significant up-regulation of core compounds from the Ras/ PI3K-Akt and mTOR signaling pathways during the cell division course of multinucleate secondary plasmodia.

The recent studies show that the PI3K pathway and the downstream pathways are often deregulated in human cancer cells. As the key component of these signaling cascades, PI3K an important target for therapeutic interventions [32, 41]. To date, several compounds that directly inhibit PI3K-Akt activity have been developed. In preclinical, phase I or II clinical trials, they have shown good anti-tumor efficacy, such as inducing cell cycle arrest or apoptosis in human cancer cells in vitro and in vivo [43-45]. GDC-0032 is a potent and selective inhibitor of Class I PI3K $\alpha, \delta$, and $\gamma$ isoforms. Preclinical data show that the combination of GDC-0032 enhances the activity of other inhibitor medication resulting in tumor regression and tumor growth delay $[34,35]$. Intriguingly, the present results show that GDC-0032 can block cell proliferation course of multinucleate secondary plasmodia and relieve the clubroot symptom of the host plants. Our findings indicate that the PI3K related signaling transduction pathways were specially required by $P$. brassicae during the multinucleate plasmodium stage of cortical infection, but not in the root hair infection stage. This is consistent with the distinct activation of proto-oncogenes and related pathways during the development of multinucleate plasmodium with a rapidly proliferating cell type.

Our research highlights the highly concordant mechanism of cell development regulated by the PI3K-Akt signaling pathway between protists and metazoans, and provides insight into the convergent evolution of this regulatory mechanism. Thus, PI3K-Akt-mediated regulation of the transition from normal cell development to rapid proliferation (such as the cell division of multinucleate secondary plasmodia of $P$. brassicae and tumorigenesis of mammalian cells) shares a common developmental mechanism. In the future, the plasmodiophorid material of $P$. brassicae could be a potential model system for studies of the PI3K-Akt signaling pathway mechanisms involved in mammalian cancer.

\section{Conclusions}

Using a multi-omics analysis strategy, we provide an important comprehensive insight into the critical multinucleate cell division life-style of the obligate uncultivable protist pathogen, $P$. brassicae. Our finding that the special activation of proto-oncogenes is important in the development of $P$. brassicae will undoubtedly inform future research on novel regulation mechanisms involved in the growth and development of unicellular organisms.

\section{Methods}

\section{Collection of field populations and isolation of single spores}

$P$. brassicae strain ZJ-1 resting spores were maintained at $-20{ }^{\circ} \mathrm{C}$ in sterilized double-distilled water containing $50 \mu \mathrm{g} . \mathrm{mL}^{-1}$ cefotaxime sodium. The details of the strain and the inoculation methods have been previously published [46].

\section{Developmental stage-specific sample preparation}

To prepare resting spore stage samples, the resting spores were extracted from single spore isolated from plant root clubroot as previously described [46]. For the collection of germinating resting spore stage samples, the purified resting spores were thawed at $4{ }^{\circ} \mathrm{C}$ for $48 \mathrm{~h}$ followed by $24 \mathrm{~h}$ at room temperature in a root exudate solution that allow germination in a dark environment. The root tissues of the prepared seeds were immersed in $2.0 \mathrm{~mL}$ Eppendorf tubes with the treated germinating spores $\left(10^{7}\right.$ spores. $\left.\mathrm{mL}^{-1}\right)$. Samples were harvested after $24 \mathrm{~h}$ when microscopy examination revealed appreciable aggregation and adsorption in root tissues of the germinating resting spores. To prepare the IN root samples for RNA extraction, seeds of oilseed rape (Brassica napus) were surface sterilized in $1 \% \mathrm{NaClO}$ for $5 \mathrm{~min}$, washed with distilled water, and germinated on moistened filter paper for 6 days in a growth chamber maintained at $22{ }^{\circ} \mathrm{C} / 20^{\circ} \mathrm{C}$ (day/night) with a 14 -h photoperiod and $80 \%$ relative humidity. Some of the seeds were transplanted to autoclaved potting mix in 60 cell $(4 \mathrm{~cm} \times$ $3.5 \mathrm{~cm} \times 6 \mathrm{~cm}$ ) plastic pot trays in a controlled environment growth chamber (HP300GS-C; Ruihua Instrument and Equipment, Wuhan, China) at a constant $20{ }^{\circ} \mathrm{C}$ with a 14 -h photoperiod and $80 \%$ relative humidity. Samples were watered once daily. Nineteen days after sowing, the plants were inoculated with resting spores derived from single spore ZJ-1 strain $\left(10^{7}\right.$ spores. $\left.\mathrm{mL}^{-1}\right)$. After inoculation, the plants were 
grown in the glasshouse conditions described above. Root masses were collected from at least 50 plants at $21 \mathrm{dpi}$, when signs of secondary infection were visible. Roots were extensively washed in tap water and inspected microscopically to ensure the absence of successful infection of pathogens. Fine root tissues were trimmed away.

\section{DNA and RNA extraction}

DNA was extracted from resting spores of the strain ZJ-1 using a modified CTAB method [47] and stored at $-20^{\circ} \mathrm{C}$. Total RNA was extracted with RNAiso Plus (Takara, Dalian, China) according to the manufacturer's protocols from the developmental stage-specific samples described above. The pellet was resuspended in 20$30 \mu \mathrm{L}$ of diethyl pyrocarbonate-treated, RNase-free water and homogenized by pipetting 20-30 times. Each sample was stored at $-80^{\circ} \mathrm{C}$. RNA quantity and quality was assessed using a spectrophotometer (NanoDrop Technologies, Inc. Wilmington, DE USA) and by $1.5 \%$ $(w / v)$ agarose gel electrophoresis.

\section{Transcriptome expression analysis}

We collected samples from three specific infection stages: resting spore stage, primary zoospore stage, and early cortical infection stage. Total RNA samples of three biological replicates for each stage were prepared. According to the manufacturer's instructions (Illumina, San Diego, CA), an RNA-seq library was prepared, followed by sequencing on an Illumina NextSeq 500 platform for paired-end $2 \times 150 \mathrm{bp}$ sequencing, which was performed at Shanghai Personal Biotechnology Co., Ltd. (Shanghai, China). The RNA-Seq raw reads were processed to obtain high quality reads by removing the adapter sequences and low-quality bases at the $3^{\prime}$ end and trimming low-quality bases $(\mathrm{Q}<20)$ from the $3^{\prime}$ to $5^{\prime}$ ends of the remaining reads. Reads containing ' $\mathrm{N}$ ' and greater than $50 \mathrm{bp}$ were filtered out. The resulting reads were considered for analysis. The filtered reads were mapped to the $P$. brassicae genome using Tophat v2.0.9 (http://tophat.cbcb.umd.edu/) [48]. The analysis of transcriptome differential expression was conducted with HTSeq (http://www-huber.embl.de/users/anders/ HTSeq) [49] and DESeq (http://www-huber.embl.de/ users/anders/DESeq) [50]. DESeq based on the theory of negative binomial distribution was used to identify the DEGs and their corresponding P-values [51]. The DEGs were selected with the standard: $P$-value $\leq 0.05$ and the absolute value of $\log _{2}$ Fold Change $\geq 1$. GO term enrichment analysis first mapped all DEGs to GO terms in the database (http://www.geneontology.org/), calculating gene numbers for every term, then used the hypergeometric test to identify significantly enriched GO terms in DEGs compared to the genome background. The KEGG pathway enrichment analysis identified significantly enriched pathways of DEGs compared with the entire genome background. To analyze gene expression data and genes with similar functions, we exploited hierarchical clustering methods based on transcriptome expression data. To compare the expression pattern of each gene between samples, the abundance of each transcript was normalized by reads per kilobase of transcript per million mapped reads (RPKM) [52]. The heat map of the clustered genes and samples was generated by the MultiExperiment Viewer v4.9 software package [53]. An average-linkage hierarchical clustering method was used, and Pearson's correlation coefficient (the distance metric is the default) was employed to measure the similarity of the expressed genes.

\section{Quantitative RT-PCR validation}

qRT-PCR primers were designed to generate amplicons to validate the RNA-seq data (Additional file 3: Table S1). For RT-PCR and qRT-PCR, $5 \mu \mathrm{g}$ of total RNA was reverse transcribed into first-strand cDNA using the oligo (dT) primer and M-MLV Reverse Transcriptase according to the manufacturer's instructions (TransScript, Beijing, China). All qRT-PCR experiments were run using SYBR Green Real-Time PCR Master Mix (Bio-Rad, Hercules, CA, USA) in $20 \mu \mathrm{L}$ reactions with the CFX96 ${ }^{\text {ma }}$ real-time PCR detection system (Bio-Rad). The $P$. brassicae actin gene was used as an internal control to normalize the expression data. Data was acquired and analyzed using the Bio-Rad CFX Manager ${ }^{\text {rm }}$ Software (version 2.0). The relative expression level of each target gene was quantified by the comparative CT method $\left(2^{-\Delta \Delta C t}\right)$ [54]. The relative expression levels of each gene were validated for the RNA-seq data.

\section{Symptom quantification during treatment with PI3K antagonist}

At 28 days after PI3K inhibitor treatment, growth and development status of oilseed rape plants were checked. A group treated with dimethylsulfoxide (DMSO) was the control. The root tissues of treated plants were harvested and the expression level of the PI3K gene (XM_013869861.1) from B. napus was quantified by qRT-PCR as described above. The effect of the PI3K inhibitor on resting spore germination rate and root hair infection rate were analyzed as previously described $[55,56]$. At 10 days after germination, the prepared plants were inoculated with the pretreatment resting spores diluted to $10^{7}$ spores. $\mathrm{mL}^{-}$ ${ }^{1}$ with modified 1/2 Hoagland nutrient solution and inhibitor solution (GDC-0032: $100 \mathrm{nM}$, MedChemExpress) in $10 \mathrm{~mL}$ EP tubes. As a parallel control, 1/2 
Hoagland nutrient solution and equivalent DMSO treatment was set as the mock-treated group under the same condition. The CK group (non-inoculated) was added to EP tubes contained equivalent volumes of $1 / 2$ Hoagland nutrient solution and inhibitor solution. Solutions in the EP tubes were refreshed every 7 days. The disease index (DI) was calculated by categorizing the individual roots at 21 and 28 dpi into five classes: 0 (no symptoms); 1 (very small clubs, mainly on lateral roots that do not impair the main root); 2 (small clubs covering the main root and few lateral roots); 3 (medium sized to bigger clubs, also including the main root and hypocotyl, fine roots are partly unaffected, plant growth may be impaired); 4 (severe clubs in lateral, main root, hypocotyls or rosette, fine roots completely destroyed, plant growth is affected) [57], using the following formula:

$$
\mathrm{DI}=\left(1 \mathrm{n}_{1}+2 \mathrm{n}_{2}+3 \mathrm{n}_{3}+4 \mathrm{n}_{4}\right) 100 / 4 \mathrm{~N}_{\mathrm{t}}
$$

where $\mathrm{n}_{1}-\mathrm{n}_{4}$ are the numbers of plant in the indicated classes and $N_{t}$ is the total number of plant tested. At 28 days after infection, all seedlings were harvested and the clubroot symptoms were investigated by phytopathological analysis. The plants were cut at the top of the hypocotyl into shoots and roots. For quantitative estimation, genomic DNA was prepared from the pool of at least 30 root samples. The abundance of the actin gene of $P$. brassicae, which represents the accumulation amount of the pathogen in the root was normalized to the actin gene of $B$. napus. A similar result was derived from three independent biological experiments. For each biological experiment, at least 30 plants were analyzed.

\section{Additional files}

Additional file 1: Figure S1. Heatmap of DEGs of $P$. brassicae at three stages. IN, multinucleate secondary plasmodia stage in plant cortical cells; GS, germinating resting spores stage when the resting spores germinating and releasing primary zoospores; and RS, resting spores stage. (TIF $1974 \mathrm{~kb}$ )

Additional file 2: Figure S2. Validation of RNA-seq results of $P$. brassicae by qRT-PCR. Comparison of expression levels for the randomly selected 12 genes from the three different samples (RS, GS and IN) were measured by RNA-seq data (gray line chart) and qRT-PCR data (black histogram). The $P$. brassicae actin gene was used as an internal control to normalize the expression level. Data from qRT-PCR represent the means and standard deviations. Pearson's correlation coefficient (R-value) was used to measure the consistency of the RNA-seg data and qRT-PCR. See Additional file 3: Table $\mathrm{S} 1$ for primer information. (TIF $736 \mathrm{~kb}$ )

Additional file 3: Table S1. Genes examined and primer pairs used in this study. (DOCX $38 \mathrm{~kb})$

Additional file 4: Table S2. The genes involve in Cancers related pathways on the genome of $P$. brassicae and corresponding expression pattern. (DOCX $32 \mathrm{~kb})$

Additional file 5: Table S3. The amino acid sequences encoded by genes involved in cancer-related signaling pathways in $P$. brassicae. (DOCX $26 \mathrm{~kb})$
Additional file 6: Table S4. Alignments of $P$. brasicae proteins associated with cancer-related signaling pathways with their homologs. (DOCX $105 \mathrm{~kb}$ )

Additional file 7: Figure S3. Effect of PI3K inhibitor treatment on the growth, development of oilseed rape plants, resting spores germination rate and root hair infection rate of $P$. brassicae. a Growth and development status of oilseed rape plants treated with PI3K inhibitor (right). MOCK (DMSO) treatment served as control (left). The pictures of plants were taken at 28 day after treatment. $B a r=1.5 \mathrm{~cm}$. b At 28 day after treatment, the roots of MOCK treated plants and inhibitor treated plants were harvested. The expression level of Cyclin gene (XM_013809141.1, downstream gene of PI3K signaling pathway) in B. napus with MOCK and inhibitor treatment was quantified by qPCR. The actin gene of $B$. napus was used as control to normalize the expression level. Data represent the means and standard deviations. The expression level of MOCK treated group was set as 1.0. Statistically significant difference of data between MOCK and inhibitor treated groups was compared, same letter in the graph indicates no significant differences at the level of $P=0.05$. $\mathbf{c}$-d Resting spores germination rate and root hair infection rate of $P$. brassicae were compared between $\mathrm{H}_{2} \mathrm{O}, \mathrm{MOCK}$ and PI3K-Inhibitor treated groups. At 6 day, the treated spores were stained with orcein (Sigma-Aldrich Canada). The germination rate of spores was counted under microscope. At $7 \mathrm{dpi}$, the roots of oilseed rape plants were stained with Trypan Blue, then the root hair infection rate was counted with microscopic examination. The graphic data represent the means and standard deviations from three biological replicates. At the level of $P=0.05$, statistically significant differences of data between $\mathrm{H}_{2} \mathrm{O}$, MOCK and inhibitor treated groups were compared, same letters in the graph indicate no significant differences. (TIF $642 \mathrm{~kb}$ )

\section{Acknowledgments}

We thank all the reviewers for the valuable suggestions in improving the manuscript and Dr. Huiquan Liu in Northwest Agriculture and Forestry University for the help in data analysis.

\section{Funding}

This research was funded by the National Key R \& D Program [grant number No. 2017YFD0200600], the Fundamental Research Funds for the Central Universities [grant number No. 2662015PY117] and the earmarked fund for China Agriculture Research System [Grant number CARS-13].

\section{Availability of data and materials}

The de novo Whole Genome Shotgun project data has been released and deposited at DDBJ/ENA/GenBank under the accession MCBL00000000. The NGS expression raw data sets used in this study were deposited in NCBI's SRA database under accession number PRJNA331021.

\section{Authors' contributions}

$D J, T C$ and $K B$ designed the experiment. KB performed most of the experiments. $K B, Z H, Z G, Y Z, J C$ and $J X$ analyzed the data. $K B$, YF and DJ wrote the manuscript. All authors read and approved the final manuscript.

\section{Ethics approval and consent to participate}

Not applicable.

\section{Consent for publication}

Not applicable.

\section{Competing interests}

The authors declare no conflict of interest. The founding sponsors had no role in the design of the study; in the collection, analyses, or interpretation of data; in the writing of the manuscript, and in the decision to publish the results.

\section{Publisher's Note}

Springer Nature remains neutral with regard to jurisdictional claims in published maps and institutional affiliations. 
Received: 27 June 2018 Accepted: 23 November 2018 Published online: 06 December 2018

\section{References}

1. Burki F, Kudryavtsev A, Matz MV, Aglyamova GV, Bulman S, Fiers M, Keeling PJ, Pawlowski J. Evolution of Rhizaria: new insights from phylogenomic analysis of uncultivated protists. BMC Evol Biol. 2010;10:377.

2. Hwang SF, Strelkov SE, Feng J, Gossen BD, Howard RJ. Plasmodiophora brassicae: a review of an emerging pathogen of the Canadian canola (Brassica napus) crop. Mol Plant Pathol. 2012;13:105-13.

3. Rolfe SA, Strelkov SE, Links MG, Clarke WE, Robinson SJ, Djavaheri M, Malinowski R, Haddadi P, Kagale S, Parkin IAP. The compact genome of the plant pathogen Plasmodiophora brassicae is adapted to intracellular interactions with host Brassica spp. BMC Genomics. 2016;17:1-15.

4. Donald EC, Porter IJ. Clubroot in Australia: the history and impact of Plasmodiophora brassicae in Brassica crops and research efforts directed towards its control. Can J Plant Pathol. 2014;36:66-84.

5. Dixon GR. The occurrence and economic impact of Plasmodiophora brassicae and clubroot disease. J Plant Growth Regul. 2009;28:194-202

6. Dixon GR. Clubroot (Plasmodiophora brassicae Woronin)-an agricultural and biological challenge worldwide. Can J Plant Pathol. 2014;36:5-18.

7. Pasold S, Siegel I, Seidel C, Ludwig-Muller J. Flavonoid accumulation in Arabidopsis thaliana root galls caused by the obligate biotrophic pathogen Plasmodiophora brassicae. Mol Plant Pathol. 2010;11:545-62.

8. Ludwig-Müller J, Bendel U, Thermann P, Ruppel M, Epstein E, Hilgenberg W. Concentrations of indole-3-acetic acid in plants of tolerant and susceptible varieties of Chinese cabbage infected with Plasmodiophora brassicae Woron. New Phytol. 1993;125:763-9.

9. Schuller A, Ludwig-Müller J. A family of auxin conjugate hydrolases from Brassica rapa: characterization and expression during clubroot disease. New Phytol. 2006;171:145-57

10. Siemens J, Keller IJ, Kunz S, Schuller A, Nagel W, Schmulling T, Parniske M, Ludwig-Muller J. Transcriptome analysis of Arabidopsis clubroots indicate a key role for cytokinins in disease development. Mol Plant-Microbe Interact. 2006:19:480-94.

11. Chen SW, Liu T, Gao Y, Zhang C, Peng SD, Bai MB, Li SJ, Xu L, Zhou XY, Lin LB. Discovery of clubroot-resistant genes in Brassica napus by transcriptome sequencing. Genet Mol Res. 2016;15:3.

12. Kageyama K, Asano T, Dixon GR. Life cycle of Plasmodiophora brassicae. J Plant Growth Regul. 2009;28:203-11.

13. Buczacki ST. Plasmodiophora: an inter-relationship between biological and practical problems. Zoosporic Plant Pathogens A Modern Perspective. Edited by Buczaki S.T. London: Academic press. 1983;161-191.

14. Schwelm A, Fogelqvist J, Knaust A, Jülke S, Lilja T, Bonillarosso G, Karlsson M Shevchenko A, Dhandapani V, Choi SR. The Plasmodiophora brassicae genome reveals insights in its life cycle and ancestry of chitin synthases. Sci Rep. 2015;5:11153.

15. Simpson C. The evolutionary history of division of labour. Proc R Soc B Biol Sci. 2012;279:116-21.

16. Merlo LMF, Pepper JW, Reid BJ, Maley CC. Cancer as an evolutionary and ecological process. Nat Rev Cancer. 2006;6:924-35.

17. Leroi AM, Koufopanou V, Burt A. Cancer selection. Nat Rev Cancer. 2003;3:226-31.

18. Hanahan D, Weinberg RA. The hallmarks of Cancer. Cell. 2000;100:57-70.

19. Davies PC, Lineweaver $\mathrm{CH}$. Cancer tumors as Metazoa 1.0: tapping genes of ancient ancestors. Phys Biol. 2011;8(1):015001.

20. Hartl M, Mitterstiller AM, Valovka T, Breuker K, Hobmayer B, Bister K. Stem cell-specific activation of an ancestral myc protooncogene with conserved basic functions in the early metazoan Hydra. Proc Natl Acad Sci U S A. 2010;107:4051-6.

21. Srivastava M, Simakov O, Chapman J, Fahey B, Gauthier MEA, Mitros T, Richards GS, Conaco C, Dacre M, Hellsten U. The Amphimedon queenslandica genome and the evolution of animal complexity. Nature. 2010;466:720-6.

22. Gaspar $T$, Hagège $D$, Kevers $C$, Penel $C$, Crèvecoeur $M$, Engelmann I, Greppin $\mathrm{H}$, Foidart JM. When plant teratomas turn into cancers in the absence of pathogens. Physiol Plant. 1991;83:696-701.

23. Doonan J, Hunt T. Cell cycle. Why don't plants get cancer? Nature. 1996;380:481-2.

24. Kinne O, Lauckner G. Diseases of marine animals. Volume I. General aspects, Protozoa to Gastropoda. Diseases of Marine Animals; 1980.

25. Gutierrez C. Coupling cell proliferation and development in plants. Nat Cell Biol. 2005;7:535-41.

26. Garber RC, Aist JR. The ultrastructure of mitosis in Plasmodiophora brassicae (Plasmodiophorales). J Cell Sci. 1979;40:89-110.
27. Asano T, Kageyama K Growth and movement of secondary plasmodia of Plasmodiophora brassicae in tumip suspension-culture cells. Plant Pathol. 2006:55:145-51.

28. Kern F, Doma E, Rupp C, Niault T, Baccarini M. Essential, non-redundant roles of B-Raf and Raf-1 in Ras-driven skin tumorigenesis. Oncogene. 2013;32:2483-92.

29. Thompson CB, Challoner PB, Neiman PE, Groudine M. Expression of the Cmyb proto-oncogene during cellular proliferation. Nature. 1986;319:374-80.

30. Nakano K, Uchimaru K, Utsunomiya A, Yamaguchi K, Watanabe T. Dysregulation of c-Myb pathway by aberrant expression of proto-oncogene MYB provides the basis for malignancy in adult T-cell leukemia/lymphoma cells. Clin Cancer Res. 2016;22(23):5915-28.

31. Lim KH, Counter CM. Reduction in the requirement of oncogenic Ras signaling to activation of PI3K/AKT pathway during tumor maintenance. Cancer Cell. 2005:8:381-92.

32. Shukla S, Maclennan GT, Hartman DJ, Fu P, Resnick MI, Gupta S. Activation of PI3K-Akt signaling pathway promotes prostate cancer cell invasion. Int J Cancer J Int Du Cancer. 2007;121:1424-32.

33. Zhao B, Tumaneng K, Guan KL. The hippo pathway in organ size control, tissue regeneration and stem cell self-renewal. Nat Cell Biol. 2011;13:877-83.

34. Ndubaku CO, Heffron TP, Staben ST, Baumgardner M, Blaquiere N, Bradley E, Bull R, Do S, Dotson J, Dudley D. Discovery of 2-\{3-[2-(1-isopropyl-3-methyl1H-1,2-4-triazol-5-yl)-5,6- dihydrobenzo [f] imidazo [1,2-d] [1,4] oxazepin-9yl]-1H-pyrazol-1-yl\}-2-methylpropanamide (GDC-0032): a $\beta$-sparing phosphoinositide 3-kinase inhibitor with high unbound exposure and robust in vivo antitumor activity. J Med Chem. 2013;56(11):4597-610.

35. Zumsteg Z, Morse N, Krigsfeld G, Gupta G, Higginson D, Lee NY, Morris L, Ganly I, Shiao SL, Powell SN, Chung CH, Scaltriti M, Baselga J. Taselisib (GDC-0032), a potent $\beta$-sparing small molecule inhibitor of PI3K, radiosensitizes head and neck squamous carcinomas containing activating PIK3CA alterations. Clin Cancer Res. 2015;22(8):2009-19.

36. Weinberg RA. Oncogenes and the molecular biology of cancer. J Cell Biol. 1983;97:1661-2.

37. Nesbit CE, Tersak JM, Prochownik EV. MYC oncogenes and human neoplastic disease. Oncogene. 1999;18:3004-16.

38. Dang CV. The interplay between MYC and HIF in the Warburg effect. Nat Rev Cancer. 2008:8:51-6.

39. Blume-Jensen $P$, Hunter T. Oncogenic kinase signalling. Nature. 2001;411:355-65.

40. Abrahim D, Serdar A, Damla B, Turhan Ç, Cem S, Narçin Palavan U. Apoptosis detection by TUNEL assay in BPH patients. J Cell Mol Biol. 2004;2:103-7.

41. Zhu W, Shao Y, Ming Y, Jia M, Yu P. Asparaginyl endopeptidase promotes proliferation and invasiveness of prostate cancer cells via PI3KAKT signaling pathway. Gene. 2016;594:176-82.

42. Testa JR. Bellacosa A. AKT plays a central role in tumorigenesis. Proc Natl Acad Sci U S A. 2001;98:10983-5.

43. Jamieson S, Flanagan JU, Kolekar S, Buchanan C, Kendall JD, Lee WJ, Rewcastle GW, Denny WA, Singh R, Dickson J. A drug targeting only p110a can block phosphoinositide 3-kinase signalling and tumour growth in certain cell types. Biochem J. 2011;438:53-62.

44. Smith GC, Ong WK, Rewcastle GW, Kendall JD, Han W, Shepherd PR. Effects of acutely inhibiting PI3K isoforms and mTOR on regulation of glucose metabolism in vivo. Biochem J. 2011:442:161-9.

45. Sgnaolin V, Pereira TC, Bogo MR, Zanin R, Battastini AM, Morrone FB, Campos MM. Functional and molecular characterization of kinin B1 and B 2 receptors in human bladder cancer: implication of the PI3KY pathway. Investig New Drugs. 2013:31:812-22.

46. Bi K, He Z, Gao Z, Zhao Y, Fu Y, Cheng J, Xie J, Jiang D, Chen T. Integrated omics study of lipid droplets from Plasmodiophora brassicae. Sci Rep. 2016;6:36965.

47. Russell J, Bulman S. The liverwort marchantia Foliacea forms a specialized symbiosis with Arbuscular Mycorrhizal fungi in the genus Glomus. New Phytol. 2004;165:567-79.

48. Trapnell C, Pachter L, Salzberg SL. TopHat: discovering splice junctions with RNA-Seq. Bioinformatics. 2009:25(9):1105-11.

49. Anders S, Pyl PT, Huber W. HTSeq-A Python framework to work with highthroughput sequencing data. Bioinformatics. 2014;31(2):166-9.

50. Anders S, Huber W. Differential expression analysis for sequence count data. Genome Biol. 2010;11(10):R106.

51. Soneson C, Delorenzi M. A comparison of methods for differential expression analysis of RNA-seq data. BMC Bioinformatics. 2013;14:775.

52. Mortazavi A, Williams BA, Mccue K, Schaeffer L, Wold B. Mapping and quantifying mammalian transcriptomes by RNA-Seq. Nat Methods. 2008:5:621-8.

53. Saeed Al, Sharov V, White J, Li J, Liang W, Bhagabati N, Braisted J, Klapa M, Currier T, Thiagarajan M. TM4: a free, open-source system for microarray data management and analysis. BioTechniques. 2003;34:374-8. 
54. Livak KJ, Schmittgen TD. Analysis of relative gene expression data using real-time quantitative PCR and the 2 (-Delta Delta C (T)). Methods. 2001;25(4):402-8.

55. Feng J, Hwang R, Hwang SF, Strelkov SE, Gossen BD, Zhou QX, Peng G. Molecular characterization of a serine protease Prol from Plasmodiophora brassicae that stimulates resting spore germination. Mol Plant Pathol. 2010;11:503-12.

56. Chen T, Bi K, He Z, Gao Z, Zhao Y, Fu Y, Cheng J, Xie J, Jiang D. Arabidopsis mutant bik1 exhibits strong resistance to Plasmodiophora brassicae. Front Physiol. 2016;7:539.

57. Klewer A, Luerben $\mathrm{H}$, Graf $\mathrm{H}$, Siemens J. Restriction fragment length polymorphism markers to characterize Plasmodiophora brassicae single-spore isolates with different virulence patterns. J Phytopathol. 2009;149:121-7.

Ready to submit your research? Choose BMC and benefit from:

- fast, convenient online submission

- thorough peer review by experienced researchers in your field

- rapid publication on acceptance

- support for research data, including large and complex data types

- gold Open Access which fosters wider collaboration and increased citations

- maximum visibility for your research: over $100 \mathrm{M}$ website views per year

At BMC, research is always in progress.

Learn more biomedcentral.com/submissions 